\title{
Die internationale Produkthaftung nach Inkrafttreten der Rom II-VO im Vergleich zu der Rechtslage in den USA
}

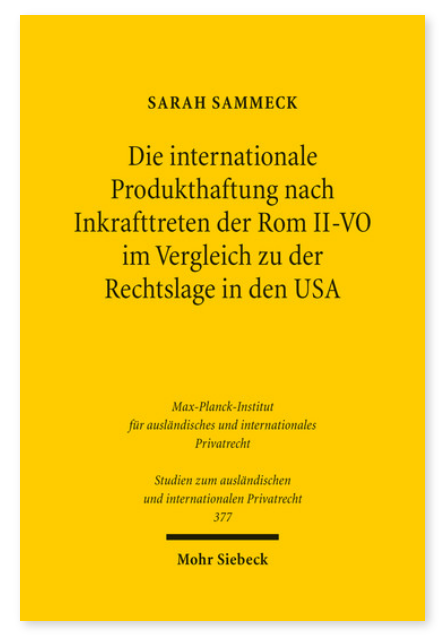

2017. XXIII, 218 Seiten. StudIPR 377

ISBN 978-3-16-154574-0

DOI 10.1628/978-3-16-154574-0

eBook PDF $74,00 €$

ISBN 978-3-16-154462-0

fadengeheftete Broschur 74,00€
Zur Bestimmung des anwendbaren Rechts in grenzüberschreitenden Produkthaftungsfällen hat der europäische Gesetzgeber mit Art. 5 der Rom II-VO eine komplexe Kollisionsnorm geschaffen, die sehr kontrovers diskutiert wird. Sarah Sammeck geht der Frage nach, ob die Kollisionsnorm des Art. 5 Rom II-VO mit seiner starren Anknüpfungssystematik oder die flexibleren Ansätze in den Bundesstaaten New York und Louisiana die überzeugendere Lösung zur Ausbalancierung der antagonistischen Regelungsziele Vorhersehbarkeit und Einzelfallgerechtigkeit bereitstellen und zu einem angemessenen Ausgleich der Interessen der Beteiligten eines Produkthaftungsfalles führen. Die vergleichende Bewertung zeigt, dass es aufgrund der Vielfalt kollisionsrechtlicher Sachverhalte aus dem Bereich der Produkthaftung unangemessen ist, nach Art. 5 Rom II-VO schematisch einzelne Anknüpfungsmerkmale zu isolieren und unter innen eine Priorisierung vorzunehmen. Die Autorin kommt zu dem Ergebnis, dass die Eröffnung der Möglichkeit einer vielfältigeren Kombination von Anknüpfungsmomenten kodifizierbar ist und nicht zwangsläufig zu Lasten der Vorhersehbarkeit und damit der Rechtssicherheit gehen muss.

Sarah Sammeck Studium der Rechtswissenschaften in Hamburg; 2003-04 Studienaufenthalt an der Università Luiss Guido Carli in Rom; Referendarin am OLG Celle; 2009 zweites juristisches Staatsexamen, 2010-11 Forschungsaufenthalt als Visiting Research Scholar an der Fordham Law School, New York; 2015 Promotion; seit 2016 Geschäftsführerin der DeutschAmerikanischen Juristen-Vereinigung e.V.(DAJV).
Jetzt bestellen:

https://mohrsiebeck.com/buch/die-internationale-produkthaftung-nach-inkrafttreten-der-rom-ii-vo-im-vergleich-zu-derrechtslage-in-den-usa-9783161545740?no_cache $=1$

order@mohrsiebeck.com

Telefon: +49 (0)7071-923-17

Telefax: $+49(0) 7071-51104$ 